ISSN 0819-2642

ISBN 0734026390

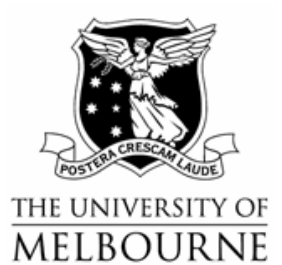

THE UNIVERSITY OF MELBOURNE

DEPARTMENT OF ECONOMICS

RESEARCH PAPER NUMBER 981

JANUARY 2007

Models of Labour Services and

Estimates of Total Factor Productivity

by

Robert Dixon

\&

David Shepherd

Department of Economics

The University of Melbourne

Melbourne Victoria 3010

Australia. 


\title{
Models of Labour Services and Estimates of Total Factor Productivity
}

\author{
by \\ Robert Dixon and David Shepherd ${ }^{1}$ \\ University of Melbourne and University of Westminster, London
}

\begin{abstract}
This paper examines the manner in which labour services are modelled in the aggregate production function, concentrating on the relationship between numbers employed and average hours worked. It argues that numbers employed and hours worked are not perfect substitutes and that conventional estimates of total factor productivity which, by using total hours worked as the measure of labour services, assume they are perfect substitutes, will be biased when there are marked changes in average hours worked. The relevance of the theoretical argument is illustrated using data for the United States and the United Kingdom.
\end{abstract}

\section{JEL Classification Numbers}

O4, 047, E23

\section{Key Words}

Labour Services, Production Function, Total Factor Productivity

\section{Corresponding Author}

Dr Robert Dixon

Email: r.dixon@unimelb.edu.au

\footnotetext{
${ }^{1}$ We are grateful to Nisvan Erkal and Peter Lloyd for helpful comments on an earlier version.
} 


\section{Models of Labour Services and Estimates of Total Factor Productivity}

\section{Introduction}

Recent contributions to the analysis of total factor productivity have emphasised that productivity estimates are sensitive to alternative specifications of the factor inputs. A number of papers have attempted to obtain a more accurate and more detailed picture of the behaviour and determinants of TFP growth by considering issues such as: the appropriate measurement of the capital stock, the use of capital service flows rather than stocks, the specification of technological embodiment, the impact of allowing for quality differences in the labour input, the importance of developments in Information and Communications Technology and the relevance of foreign investment and foreign ownership of industry. Examples of recent papers along these lines include: Oulton (2001, 2002), O’Mahony \& de Boer (2002a, 2002 b) Bank of England (2003), Basu et al (2003), Disney et al (2003), Lau \& Vaze (2003), Ferrett (2004), Groth et al (2004), Macdonald \& Salt (2004) and Metz et al (2004).

Our contribution to this developing literature is to argue that traditional calculations of total factor productivity incorporate an inappropriate specification of the labour services input in the production function. Specifically, we argue that conventional estimates of total factor productivity are based on the implicit assumption that numbers of employees and (average) hours are perfect substitutes, and that this assumption is not supported by either economic theory or empirical evidence. We demonstrate that, when average hours are changing, conventional measures of total factor productivity growth are biased and the direction of the bias is such that productivity growth is over-estimated during periods when average hours worked are falling and under-estimated when average hours are rising. The theoretical analysis is illustrated with reference to data for the United Kingdom and the United States.

\section{Estimating Total Factor Productivity}

Total factor productivity (TFP) can be calculated as:

$$
\operatorname{TFP}_{t}=\frac{V_{t}}{K_{t}^{w_{K t}} L_{t}^{w_{L t}}}
$$

where $V$ is real output (gross value added), $K$ is real capital input, $L$ is labour services, $w_{K}$ and $w_{L}$ are the factor input weights for capital and labour respectively. In this formulation, it is 
usual to regard labour services $(L)$ as total hours worked, measured as the product of the number of persons employed $(N)$ and average hours worked $(h)$, so that:

$$
L_{t}=h_{t} N_{t}
$$

and so we may say that the conventional measure of $T F P$ is calculated as:

$$
\operatorname{TFP}_{t}=\frac{V_{t}}{K_{t}^{w_{K t}}\left(h_{t} N_{t}\right)^{w_{L t}}}
$$

Equations (2) and (3) implicitly assume that the elasticity of output with respect to (average) hours worked is the same as the elasticity of output with respect to the number of workers employed. This is equivalent to assuming that numbers employed and hours worked are perfect substitutes and that the firm would be indifferent between employing extra people or obtaining extra hours of work from existing employees. We regard this assumption as implausible. As we show in the next section of the paper, economic theory suggests that when there are fixed costs of employment, hours and employment are likely to be imperfect substitutes. Empirical evidence presented by Hamermesh (1993), Hart (1984) and Feldstein (1967) also supports the notion that employment and hours are not perfect substitutes. ${ }^{2}$

In this paper we adopt an alternative specification for labour services to thayt given by (2) above. We adopt the specification which was originally proposed by Ehrenberg (1971) and later utilised by Bell (1982), Calmfors \& Hoel (1988), Booth \& Ravallion (1993), Kapteyn et al (2004) and others. This specification is of the form $F(h, N)=G(h) N$, where $G(0)=0$, $G^{\prime}(h)>0, G^{\prime \prime}(h)<0$ and $\alpha=G^{\prime}(h) h / G(h)<1$. It is assumed that the elasticity of labour services $(L)$ with respect to the numbers employed $(N)$ is equal to unity. There are a number of ways this can be defended. It seems reasonable to assume that, with average hours constant, an increase in the number employed will be accompanied by an equi-proportional increase in labour services and, with constant returns to scale in the production function, an equiproportional increase in output. ${ }^{3}$ Some indirect support for this assumption can be found in

\footnotetext{
${ }^{2}$ In addition to empirical concerns we might have about the assumption that employment (number of persons) and (average) hours are perfect substitutes, Brechling (1965) and others have shown that this leads to a theoretical difficulty in that can force the labour services isoquant to have exactly the same curvature as the labour services iso-cost line - which means that the optimal combination of hours and number of workers is indeterminate.

${ }^{3}$ Another way to put this is to say that we are assuming that an increase in output by a factor of $x$, will result in an increase in the demand for employees (and capital services) by a factor of $x$, with (average) hours constant.
} 
empirical studies of the demand for labour, which typically suggest that the coefficient linking the logarithm of numbers employed with the logarithm of aggregate output is unity.

In what follows we will explore the consequences for TFP calculations of assuming that labour services evolve according to the following rule:

$$
L_{t}=A h_{t}^{\alpha} N_{t}
$$

where $A$ is a measure of worker effort or work intensity, assumed for simplicity to be constant. ${ }^{4}$ Substitution of (4) into (1) gives:

$$
\operatorname{TFP}_{t}^{*}=\frac{V_{t}}{K_{t}^{w_{K t}}\left(A h_{t}^{\alpha} N_{t}\right)^{w_{L t}}}
$$

The impact of this alternative specification of the labour services function can readily be seen by comparing the implied measures of TFP growth obtained from (3) and (5). The conventional approach, with $L=N h$, computes TFP growth from (3) as:

$$
\left(\frac{d T F P}{T F P}\right)=\frac{d V}{V}-w_{K} \frac{d K}{K}-w_{L}\left(\frac{d h}{h}+\frac{d N}{N}\right)
$$

In contrast, our preferred measure, with $L=A h^{\alpha} N$, is derived from equation (5):

$$
\left(\frac{d T F P}{T F P}\right)^{*}=\frac{d V}{V}-w_{K} \frac{d K}{K}-w_{L}\left(\alpha \frac{d h}{h}+\frac{d N}{N}\right)
$$

Subtracting (7) from (6) gives an expression for the direction and extent of the bias in the conventional estimate of technical change in the aggregate production function:

$$
\left(\frac{d T F P}{T F P}\right)-\left(\frac{d T F P}{T F P}\right)^{*}=(\alpha-1) w_{L} \frac{d h}{h}
$$

\footnotetext{
${ }^{4}$ If effort or the intensity of work is not constant this will appear as a change in TFP. This should be explored but would take us too far from the main point we are making in this paper, namely that in researching TFP it is necessary to allow for imperfect substitutability between hours and workers.
} 
According to equation (8), the two measures of $T F P$ growth yield the same result only if $\alpha=1$ and/or there have been no changes in average hours, so that $d h / h=0$. When average hours are changing, however, TFP growth will be overstated or understated according to whether $(\alpha-1) w_{L}$ is negative or positive. In order to determine the sign and extent of any bias in the conventional measure of $T F P$ growth, it is therefore necessary to evaluate the right-hand side of (8).

Although average hours worked typically have a cyclical component, there are other potential short run and long-run changes affecting hours with the result that the sign and magnitude of $d h / h$ may vary in a systematic fashion over time and across economies. Given that the size of $w_{L}$ reflects the share of labour income in total income, and must therefore be a positive fraction, it follows that $(\alpha-1) w_{L}$ is positive or negative according to whether $\alpha$ is greater than or less than unity. The next step is to look more closely at the determinants of $\alpha$, which is the elasticity of labour services with respect to hours.

\section{The Elasticity of Labour Services with Respect to Hours}

It is convenient to begin our discussion by demonstrating that the conventional specification of the labour input implies that hours and numbers employed are perfect substitutes in the provision of labour services. We have already said that labour services $(L)$ are commonly defined as the total number of hours worked, which is the product of numbers employed and average hours worked, $L=h N$. It should be noted in passing that this expression implies that the elasticity of labour services with respect to hours is unity as it can be rearranged to give the following expression for $N$ in terms of $h$ :

$$
N=\frac{L}{h}
$$

The rate at which the firm can substitute workers for hours, while holding the output of labour services constant, is given by the slope of the labour services iso-quant, which is the value of $d N / d h$ with $L$ given. Differentiating the above gives:

$$
\frac{d N}{d h}=-\frac{N}{h}
$$

and the elasticity of $N$ with respect to $h$ along the iso-quant is given by: 


$$
\frac{d N}{d h} \frac{h}{N}=-1
$$

This means that the definition of labour services as the product of average hours and employment carries an implicit assumption that the elasticity of $N$ with respect to $h$ is -1 , which is equivalent to supposing that firms regard the two 'inputs' as perfect substitutes. In the next section of the paper we show that, when there are fixed costs of employing labour, firms are unlikely to regard $N$ and $h$ as perfect substitutes in the provision of labour services.

\section{Fixed and Variable Costs of Labour}

Ignoring any distinction between ordinary hours and overtime, the firm's total labour cost $(C)$ depends upon the number of persons employed $(N)$, the weekly wage paid to labour (equal to the hourly wage $w$ multiplied by the number of hours worked $h$ ) and fixed costs $(f)$ per worker (defined as costs which do not vary with hours worked by an individual employee, such as costs of recruitment, training and firing). Total labour costs are then:

$$
C=w h N+f N
$$

Rearranging (10) gives an expression for $N$ in terms of $h$ :

$$
N=\frac{C}{w h+f}
$$

For any given labour cost budget, the rate at which the firm can trade numbers employed for hours is given by the slope of the budget line (the iso-cost curve) which is the value of $d N / d h$ when $C$ is constant. Differentiating (11) with $w$ and $C$ constant gives:

$$
\frac{d N}{d h}=-N \frac{w}{w h+f}=-\frac{N}{h} \frac{w h}{w h+f}
$$

And the elasticity of $N$ with respect to $h$ along the iso-cost curve is equal to:

$$
\frac{d N}{d h} \frac{h}{N}=-\frac{w h}{w h+f}
$$

Equation (13) shows that the value of the employment-hours elasticity is equal to the ratio of variable to total cost per worker and that this elasticity is equal to -1 only if $f=0$. In contrast, 
if there is a fixed element to employment costs, the elasticity must always be $<|1| .^{5}$ In other words, fixed employment costs imply that firms will not regard hours and employment as perfect substitutes in the provision of labour services.

\section{The Labour Services Isoquant}

Our preferred model of labour services, described by equation (4), can be rearranged to give an expression for $N$ in terms of $h$

$$
N=\left(\frac{L}{A h^{\alpha}}\right)
$$

The rate at which the firm can substitute workers for hours, while holding the output of labour services constant, is given by the slope of the iso-quant, which is the value of $d N / d h$ for a fixed level of $L$. From equation (14) this is given by:

$$
\frac{d N}{d h}=-\alpha \frac{N}{h}
$$

Differentiating (15) with respect to $h$ gives $\partial(d N / d h) / \partial h=\alpha\left(N / h^{2}\right)>0$, which means that the iso-quant in $N: h$ space is non-linear and convex. Notice also that the elasticity of $N$ with respect to $h$ along the iso-quant is equal to:

$$
\frac{d N}{d h} \frac{h}{N}=-\alpha
$$

The condition for cost minimization is obtained by setting (13) to equal (16):

$$
\frac{d N}{d h} \frac{h}{N}=-\frac{w h}{w h+f}=-\alpha
$$

Given that fixed labour costs are positive, we know that $w h /(w h+f)<1$ and hence cost minimization requires that we impose the restriction $0<\alpha<1$ on the labour services function. ${ }^{6}$

\footnotetext{
${ }^{5}$ Bell (1982, p 338) shows that this elasticity (the elasticity of $N$ with respect to $h$ ) is equal to the elasticity of total costs per worker with respect to hours as differentiating our expression for $c$ (ie equation (11)) with respect to $h$ gives $\partial c / \partial h=w$ and so $(\partial c / \partial h)(h / c)=w h / c=w h /(w h+f)$.
} 
Furthermore, we can see from (17) that $\alpha$ is actually equal in value to the ratio of the variable and total labour cost components and, if we knew that fraction, we would have an indirect estimate of $\alpha$.

\section{Estimates of TFP for the UK and the USA}

The previous analysis suggests that defining labour services as total hours worked may yield biased estimates of TFP and that the size of the bias in the measurement of TFP depends on the magnitude of the labour input weight $w_{L}$ in the production function and the size of the employment-hours elasticity $\alpha$. With constant returns to scale, the value of $w_{L}$ is given by the share of factor income accruing to labour, which can readily be calculated from available data. In the case of $\alpha$, we have shown that its value can be measured as the ratio of variable to total labour costs. The most thorough discussion we have been able to find on this subject is in Hart (1984) who suggests that for both the USA and the UK it is reasonable to put "fixed labour costs at roughly 20 percent of total variable [labour] costs”, which implies that $\alpha$ is (roughly) 0.83 .

In this section we use the assumption that $\alpha=0.83$, together with data on the other components, to compute TFP estimates for the UK and the US. For each country, we generate two series: one based on the conventional method, which assumes workers and hours are perfect substitutes, and another based on our assumption that they are imperfect substitutes. We then compare the two series and consider what they suggest about macroeconomic performance over the period. With the exception of our estimate of $\alpha$, all of the data we use is from the Total Economy Growth Accounting Database at Groningen which provides relevant data for the UK and USA for each year commencing in 1980 and ending in 2004. ${ }^{7}$ The database is described in Smith (2003) and in Timmer et al (2003). The Groningen Database has $w_{L}$ varying slightly over the period, with a mean value of 0.69 for the UK and 0.71 for the

\footnotetext{
${ }^{6}$ This is a restriction which is commonly imposed, see Ehrenberg (1971, p 16), Bell (1982, p 338) and Hart (1987, p 148) for examples. Since both curves are convex, the second-order condition necessary for an interior solution is that $\alpha\left(N / h^{2}\right)>N /\left(h^{2}+(f / w)^{2}+2 h(f / w)\right)$. This condition is satisfied if $\alpha=h /(h+(f / w))$.

7 A full description and analysis of the database can be found in Marcel P. Timmer, Gerard Ypma and Bart van Ark (2003), IT in the European Union: Driving Productivity Divergence?, GGDC Research Memorandum GD-67 (October 2003), University of Groningen, Appendix Tables, updated June 2005. Data downloaded from http://www.ggdc.net/dseries/growth-accounting.html This database was developed for a study on EU Productivity and Competitiveness: An Industry Perspective Can Europe Resume the Catching-up Process? (O'Mahony and van Ark, eds., Office for Official Publications of the European Communities, Luxembourg, 2003).
} 
USA. The relevant series for average hours in the UK and US are shown in Figure 1 below. For the UK at least there appear to be secular, and not merely cyclical, changes in average hours over the period.

\section{[FIGURE 1 NEAR HERE]}

Our analysis suggests that there is likely to be a bias in the calculation of TFP growth whenever average hours worked are rising or falling. This suggests that comparisons of TFP growth over different time periods or across countries should give some consideration to the impact of changes in patterns of hours worked. To place this in context, for the data set we are using, it is useful to look at the means of all of the years in which hours are falling and, separately, all of the years in which hours are rising. These are reported in Table 1, which shows mean TFP growth rates for the UK and the USA calculated using the conventional labour input measure (equation 6) and our preferred labour input measure (equation 7). As expected, the new estimates of TFP growth are lower than the conventional estimates when hours are falling and are higher than the conventional estimates when hours are rising. ${ }^{8}$

\section{[TABLE 1 NEAR HERE]}

In the literature it is common for researchers to calculate mean values of $T F P$ over a fixed number of years, in attempt to identify phases of faster or slower productivity growth or to assess what was happening to productivity growth over periods identified as being of interest for other reasons, such as phases of higher or lower inflation, phases when labour market conditions or macroeconomic policies were changing, and so on. For illustrative purposes, table 2 shows the mean TFP growth rates over successive 5 year periods, from 1980 to 2004 .

\section{[TABLE 2 NEAR HERE]}

A proper interpretation of these periods requires the data in table 2 to be considered in conjunction with the information on average hours shown in figure 1. In the case of the United

\footnotetext{
${ }^{8}$ It may be of concern to the reader that differences in the TFP estimates may solely be related to contraction and expansion phases of the business cycle, after all we would expect (and we observe) hours tending to fall in contractions and to rise in expansions. However for the UK at least it is clear that changes in hours are not solely related to the business cycle. Indeed, for both countries there is only a weak correlation between annual growth rates of change in output and hours. The coefficient of determination between the two is 0.47 for the UK and 0.34 for the USA.
} 
Kingdom, it would appear that average hours were generally falling over the period, with a particularly pronounced fall in hours between 1988 and 1993 (see also Timmer et al, 2003). ${ }^{9}$ This suggests that the conventional measure of TFP would exhibit an upwards bias, particularly in the late 80 s and early 90s, which is roughly what table 2 suggests. In the case of the United States, average hours show minor year to year fluctuations, but there are no pronounced trends over the entire period, apart from a modest rise between 1992 and 2000 and a fall thereafter. This suggests that we should not observe any significant difference in the TFP measures, apart from an understatement in the second half of the 1990s and an over-statement thereafter. Again, these features are broadly reflected in the results for the United States shown in table 2.

\section{Concluding Remarks}

In this paper we have demonstrated that the conventional approach to measuring total factor productivity carries the implicit assumption that employees and (average) hours are perfect substitutes. We have argued that this assumption is not supported by either economic theory or the empirical evidence and have shown that under certain assumptions (assumptions which are often made in order to facilitate computations of TFP), the elasticity of employment with respect to (average) hours is equal in value to the ratio of the variable and total labour cost components. Using data for the United States and the United Kingdom, we were able to generate alternative estimates of total factor productivity growth growth to explore the consequences of dropping the assumption of perfect substitutability between hours and workers. The results confirm that conventional measures of TFP growth, based on the implicit assumption of perfect hours-people substitutability, will tend to over-state the rate of TFP growth when average hours worked are falling and under-state TFP growth when average hours are rising. The implication of our analysis is that care should be taken when comparing productivity growth over time and between countries, to allow for the bias inherent in conventional calculations when average hours worked are changing. This is particularly pertinent when the changes in hours worked are substantial.

\footnotetext{
${ }^{9}$ Leaving aside cyclical influences, the fall in average hours worked in the UK is probably due to a combination of: the increased importance of part-time work and some reduction in full-time male work hours, driven partly by legislation and partly by choice, and structural change, which increased job choice flexibility. A more extensive discussion of changes in working hours can be found in Bishop (2004).
} 


\section{References}

Bank of England (2003) Inflation Report November 2003, Bank of England, London

Basu, S., Fernald, J., Oulton, N. Srinivasan, S. (2003) The case of the missing productivity growth: Or, does information technology explain why productivity accelerated in the United States but not the United Kingdom?, NBER Macroeconomics Annual, 18, 9-71.

Bell, D. (1982) Labour utilization and statutory non-wage costs, Economica, 49, 335-43.

Bishop, K. (2004). Working time patterns in the UK, France, Denmark and Sweden, Labour Market Trends, 112, 113-22.

Booth, A. and Ravallion, M. (1993) Employment and length of the working week in a unionized economy in which hours of work influence productivity, Economic Record, 69, 428-36.

Brechling, F. (1965) The relationship between output and employment in British manufacturing industries, Review of Economic Studies, 32, 187-216.

Calmfors, L. and Hoel, M. (1988) Work sharing and overtime, Scandinavian Journal of Economics, 90, 45-62.

Disney, R., Haskell, J. and Heden, Y. (2003) Restructuring and productivity growth in UK manufacturing, Economic Journal, 113, 666-94.

Ehrenberg, R. (1971) Fringe Benefits and Overtime Behavior, Lexington Books, Lexington, Mass.

Feldstein, M. (1967) Specification of the labour input in the aggregate production function, Review of Economic Studies, 34, 375-86.

Ferrett, R. (2004) Foreign direct investment and productivity growth: A survey of theory, Leverhulme Centre for Research on Globalisation and Economic Policy, Research Paper 2004/15, University of Nottingham.

Groth, C., Gutierrez-Domenech, M and Srinivasan, S. (2004) Measuring total factor productivity in the United Kingdom, Bank of England Quarterly Bulletin, Spring, 63-73.

Hamermesh, D. (1993) Labor Demand, Princeton University Press, Princeton.

Hart, R. (1984) The Economics of Non-Wage Labour Costs, Allen \& Unwin, London.

Hart, R. (1987) Working Time and Employment, Allen \& Unwin, Boston.

Kapteyn, A., Kalwij, A. and Zaidi, A. (2004) The myth of worksharing, Labour Economics, 11, 293-313. 
Lau, E. and Vaze, P. (2002) Accounting growth: capital, skills and output, Office for National Statistics, Occasional Paper PROD05, available at http://www.statistics.gov.uk/articles/nojournal/paper_5_TFP.pdf

Macdonald, J. and Salt, R. (2004) What next for productivity in the UK?, ECFIN Country Focus, 1, 10.

Metz. R., Riley, R. and Weale, M. (2004) Economic performance in France, Germany and the United Kingdom 1992-2002, National Institute Economic Review, 188, 83-99.

O’Mahony, M. and de Boer, W. (2002a) Britain's Relative Productivity Performance: Updates to 1999, Final Report to DTI/Treasury/ONS, National Institute of Economic and Social Research, London.

O’Mahony, M. and de Boer, W. (2002b) Britain's relative productivity performance: Has anything changed?, National Institute Economic Review, 179, 38-43.

Oulton, N. (2001) Why do foreign-owned firms in the UK have higher labour productivity?, in Inward Investment, Technological Change and Growth (Ed.) N. Pain, Palgrave, Basingstoke, pp 122-61.

Oulton, N. (2002) ICT and productivity growth in the United Kingdom, Oxford Review of Economic Policy, 18, 363-79.

Smith, J. (2003) International productivity comparisons: An examination of data sources, International Productivity Monitor, 6, 64-71.

Timmer, M., Ypma, G and van Ark, B. (2003) IT in the European Union: Driving Productivity Divergence?, GGDC Research Memorandum GD-67, October, University of Groningen, Appendix Tables, updated June 2005 http:/www.ggdc.net/dseries/growthaccounting.html 




Fig. 1. Annual hours per worker

Table 1. Alternative estimates of TFP growth in the UK and USA: 1980-2004 (Average Annual Percentage Growth Rate)

\begin{tabular}{ccccc}
\hline & UK & UK & USA & USA \\
& Equation (6) & Equation (7) & $\begin{array}{c}\text { Equation (6) } \\
\text { Equation (7) }\end{array}$ \\
\hline Falling hours & 1.06 & 0.97 & 0.67 & 0.57 \\
Rising hours & 1.70 & 1.74 & 0.99 & 1.06 \\
\hline
\end{tabular}

Table 2. Alternative estimates of TFP growth in the UK and USA: 1980-2004 (Average Annual Percentage Growth Rate)

\begin{tabular}{ccccc}
\hline & $\begin{array}{c}\text { UK } \\
\text { Equation (6) }\end{array}$ & $\begin{array}{c}\text { UK } \\
\text { Equation (7) }\end{array}$ & $\begin{array}{c}\text { USA } \\
\text { Equation (6) }\end{array}$ & $\begin{array}{c}\text { USA } \\
\text { Equation (7) }\end{array}$ \\
\hline $1980-85$ & 1.58 & 1.55 & 0.71 & 0.71 \\
$1985-90$ & 1.00 & 0.96 & 0.51 & 0.50 \\
$1990-95$ & 1.50 & 1.46 & 0.60 & 0.62 \\
$1995-00$ & 1.16 & 1.14 & 1.33 & 1.36 \\
$2000-04$ & 1.32 & 1.26 & 1.54 & 1.44 \\
\hline
\end{tabular}

